\title{
Eliminando desperdícios na biblioteca: o uso do Mapa do Fluxo de Valor (MFV) no serviço de empréstimo para educação a distância (EaD)
}

\section{Avoiding waste in the library: the usage of Value-Stream Mapping (VSM) in distance education lending service}

\author{
Crislaine Zurilda Silveira ${ }^{1}$, Jordan Paulesky Juliani ${ }^{2}$ \\ ${ }^{1}$ Universidade Federal de Santa Catarina (UFSC), Florianópolis, SC, Brasil. ORCID: https://orcid.org/0000-0003-3081-9968 \\ 2 Universidade do Estado de Santa Catarina (UDESC), Florianópolis, SC, Brasil. ORCID: https://orcid.org/0000-0001-7823-6644
}

Autor para correspondência/Mail to: Crislaine Zurilda Silveira, crislaine.bibliotecaria@gmail.com

Recebido/Submitted: 22 de fevereiro de 2021; Aceito/Approved: 22 de abril de 2021

Copyright (c) 2022 Silveira \& Juliani. Todo o conteúdo da Revista (incluindo-se instruções, política editorial e modelos) está sob uma licença Creative Commons Atribuição 4.0 Internacional. Ao serem publicados por esta Revista, os artigos são de livre uso em ambientes educacionais, de pesquisa e não comerciais, com atribuição de autoria obrigatória. Mais informações em http://revistas.ufpr.br/atoz/about/submissions\#copyrightNotice.

\begin{abstract}
Resumo
Introdução: as bibliotecas precisam gerir seus recursos de maneira racional, evitando desperdícios. Objetivo: relatar o uso do mapa do fluxo de valor (MFV) na identificação dos desperdícios e das oportunidades de melhorias envolvidas na prestação do serviço de empréstimo EaD na Biblioteca Central da UFSC. Método: foi utilizado o grupo focal para discussão e elaboração do mapa. Resultados: o mapa possibilitou identificar que o desperdício de espera é o que mais influencia nesse serviço e permitiu identificar as atividades que agregam valor ao serviço e as oportunidades de melhorias. Conclusão: o MFV pode contribuir para a identificação das oportunidades melhorias do serviço de empréstimo EaD na UFSC, no entanto, isso somente é possível com o envolvimento das pessoas que executam os processos e atividades e apoio da gestão.

Palavras-chave: Lean; Educação a distância; Biblioteca universitária; Mapa do fluxo de valor.
\end{abstract}

\begin{abstract}
Introduction: libraries need to manage their resources rationally, avoiding waste. Objective: to report the value-stream mapping usage in the waste identification and opportunities for improvement of the Distance Education's lending service at the Central Library of UFSC. Method: It applies the focus group to discuss and prepare the value-stream map. Results: the value-stream mapping permitted identifying that waiting waste was the one that most influenced this service, and it identified opportunities for improvement and benefit activities to the service. Conclusion: the value-stream mapping can contribute to identifying opportunities for improvement of the distance education lending service at UFSC. However, this is only possible with the engagement of people who execute the processes and management support activities.
\end{abstract}

Keywords: Lean; Distance Education; Academic Library; Value flow mapping.

\section{INTRODUÇÃO}

Num contexto marcado por recursos escassos e por um aumento na necessidade de informações em diferentes contextos, as bibliotecas universitárias precisam ter novas atitudes, precisam que seus profissionais adquiram novas competências, que sua gestão desenvolva métodos e práticas que visem agilizar e simplificar processos e, finalmente, mas não menos importante, que vise à aquisição e ao desenvolvimento de ferramentas tecnológicas para atender às demandas relacionadas às novas formas de ensino-aprendizagem (Marques, 2016).

Para Valentim (2017) a oferta de cursos a distância, salas de aula virtuais, materiais didáticos e científicos em repositórios institucionais, a interação com as tecnologias de informação e comunicação (TICs) móveis, por exemplo, o tablet, o smartphone, fazem com que as bibliotecas, que são tradicionalmente conhecidas por ofertar serviços aos usuários presenciais, passem a ter o desafio de atender àqueles usuários que não estão fisicamente no espaço da biblioteca, mas que necessitam ter sua formação amparada pelos seus serviços.

Com cada vez mais demandas e menos recursos, as bibliotecas precisam agilizar e simplificar seus processos para que continuem entregando valor para a universidade e, consequentemente, para os seus usuários (Marques, 2016). Por isso, é necessário que elas sejam gerenciadas de forma que seus recursos sejam utilizados de forma consciente e racional. Para tanto, o lean pode ser um caminho, pois visa eliminar os desperdícios a partir da melhoria contínua dos processos e do envolvimento das pessoas.

O lean, ou o pensamento enxuto, é uma forma de fazer cada vez mais com menos - menos esforço humano, menos equipamentos, menos tempo, menos espaço - e, ao mesmo tempo, aproximar-se cada vez mais de oferecer aos clientes exatamente o que eles desejam (Womack \& Jones, 1998). Essa filosofia de gestão é baseada no Sistema Toyota de Produção, que ficou conhecido no ocidente a partir da publicação dos livros "A máquina que mudou o mundo" e "A mentalidade enxuta ou lean thinking", ambos na década de 90. 
O Mapa do Fluxo de Valor (MFV) é uma das ferramentas bases do lean que consiste em verificar de que forma as atividades são realizadas. O MFV inicialmente foi criado com o objetivo de identificar desperdícios no ambiente da manufatura e que, posteriormente, foi adaptado para as áreas administrativas, de acordo com Keyte e Locher (2004).

Na Ciência da Informação, o uso dos princípios lean não é novidade. Greef e Freitas (2012) buscaram identificar parâmetros para qualificação da gestão e da operação de fluxos informacionais com o uso lean e Freitas, Silva, Odorczyk, e Freitas (2018) exploraram o lean como facilitador para a criação e disseminação do conhecimento organizacional. Os trabalhos de Cavaglieri e Juliani (2016, 2017a, 2017b) voltaram-se para a aplicação dos princípios e das ferramentas relacionadas ao pensamento enxuto nos arquivos. Martignago e Juliani (2019, 2020) estudaram a aplicação desse pensamento na identificação de valor na redução de desperdícios no fluxo editorial de periódicos científicos.

Já o uso do lean em bibliotecas é explorado no trabalho de Barbosa (2014), que o utilizou para avaliar o processo de aquisição de monografias para a Biblioteca do ISCTE-IUL; Durán (2014) realizou uma análise bibliográfica da aplicação dos princípios do lean em bibliotecas e centros de documentação; os autores Cabete, Cabete, e Melo (2016a, 2016b) refletiram sobre a utilização do lean em bibliotecas escolares numa perspectiva bibliográfica; Nilofar (2017) utilizou uma abordagem baseada no Lean Six Sigma para elaborar uma abordagem voltada para a tomada de decisões referentes ao uso de computadores nas bibliotecas da Universidade de Negócios de Singapura, o trabalho de Ferreira e Mota (2019) relatou o uso do lean de forma concomitante à modelagem de processo, tendo em vista identificar atividades que causavam retrabalho num serviço do Sistema de Bibliotecas, da Universidade Federal de Goiás; Regan, Goldsworthy, e Pawley (2020), usaram os princípios do lean para tornar mais eficiente a busca por evidências na literatura nos protocolos clínicos da radioterapia; por fim, o trabalho de Yeh, Arthaud-Day, e Turvey-Welch (2021) analisou os desperdícios no fluxo de aquisição de coleções eletrônicas da biblioteca da Universidade do Estado do Kansas, na perspectiva do lean.

Apesar desses trabalhos destacarem o uso do lean na Ciência da Informação, nenhum daqueles que foram usados em bibliotecas relata de forma detalhada como foi realizado o diagnóstico a partir do uso do MFV, etapa inicial de qualquer implementação da filosofia lean. Portanto, o problema deste estudo é: de que maneira o MFV pode ser usado na biblioteca?

Para responder ao problema destacado, a finalidade deste estudo é relatar o uso MFV, na identificação dos desperdícios e das oportunidades de melhorias na prestação do serviço de empréstimo voltado aos alunos da Educação a Distância (EaD) na Biblioteca Central (BC) da Universidade Federal de Santa Catarina (UFSC).

\section{LEAN THINKING}

Para Womack e Jones (1998), o lean thinking é uma forma de especificar valor, alinhar na melhor sequência as ações que criam valor, realizar essas atividades sem interrupção toda vez que alguém as solicitar e realizá-las de forma cada vez mais eficiente. O valor, nesse contexto, é entendido como aquele expresso em termos de um produto específico, quando atende às necessidades dos clientes no momento em que for requisitado (Womack \& Jones, 1998). O pensamento enxuto se desenvolve por meio de cinco princípios. São eles:

a) identificação do valor: este é o ponto de partida essencial, pois ele é o elemento definido pelo cliente do produto ou serviço final, quando sua necessidade é atendida (Greef \& Freitas, 2012; Womack \& Jones, 1998);

b) identificação da cadeia de valor: é o conjunto de atividades realizadas em sequência para desenvolver um produto ou serviço. A identificação da cadeia de valor permite identificar três tipos de atividades: aquelas que geram valor e são necessárias, pois estão diretamente associadas com o resultado final do processo; aquelas que não geram valor, mas são necessárias para a realização de todo o conjunto de tarefas; e aquelas que não geram valor e não são necessárias, por isso devem ser eliminadas imediatamente (Greef \& Freitas, 2012; Womack \& Jones, 1998);

c) fluxo: após a identificação da cadeia de valor, é necessário que as atividades fluam entre os processos. Para que isso ocorra, é preciso integrar a cadeia de valor para que os processos fluam de forma contínua, o que exige o desprendimento das estruturas funcionais e departamentalizadas (Greef \& Freitas, 2012);

d) produção puxada: este princípio do pensamento enxuto representa a realização das tarefas do processo de produção mediante a demanda pela produção ou serviço manifestada pelo cliente. Elimina-se desta forma a produção desnecessária, a produção em excesso e o tempo para a geração de itens que não foram solicitados pelo cliente (Greef \& Freitas, 2012);

e) perfeição: representa a melhoria contínua, ou seja, os processos precisam ser sempre melhorados, por isso é imprescindível o engajamento das pessoas que os executam (Womack \& Jones, 1998).

O lean está pautado na eliminação da $m u d a$, termo japonês para desperdício. Muda é qualquer atividade humana que absorve recursos, mas não cria valor como, por exemplo, erros que exigem retificação, produção de itens 
que ninguém deseja, acúmulo de mercadorias nos estoques, bens e serviços que não atendem às necessidades do cliente (Womack \& Jones, 1998).

A eliminação da muda foi a estratégia adotada pela Toyota para se tornar mais competitiva diante de um contexto japonês do pós-guerra, marcado por crises, escassez de recursos, desemprego. Com base nessa estratégia, (Ohno, 1997) definiu sete grandes classes de desperdícios, descritas na Tabela 1.

\begin{tabular}{|l|l|}
\hline Tipo de Desperdícios & Conceito \\
\hline $\begin{array}{l}\text { Desperdício de superpro- } \\
\text { dução }\end{array}$ & $\begin{array}{l}\text { Caracteriza-se pela produção de produtos em maior quantidade do que o ne- } \\
\text { cessário, ou quando não há uma demanda explícita, ou ainda, quando se produz } \\
\text { antes do tempo necessário (Ghinato, 1996; Liker, 2005). }\end{array}$ \\
\hline $\begin{array}{l}\text { Desperdício de tempo dis- } \\
\text { ponível (espera) }\end{array}$ & $\begin{array}{l}\text { Caracteriza-se quando um trabalho precisa ficar aguardando a finalização de } \\
\text { um processo ou quando ocorre um atraso no fornecimento de matéria-prima } \\
\text { (Ghinato, 1996). }\end{array}$ \\
\hline $\begin{array}{l}\text { Desperdício em trans- } \\
\text { porte }\end{array}$ & $\begin{array}{l}\text { Caracteriza-se quando há a necessidade de movimentar os produtos e matérias- } \\
\text { primas por longas distâncias. Cabe ressaltar que o transporte é uma atividade } \\
\text { que não agrega valor e que por isso deve ser minimizada ou eliminada. }\end{array}$ \\
\hline $\begin{array}{l}\text { Desperdício do processa- } \\
\text { mento em si }\end{array}$ & $\begin{array}{l}\text { Caracteriza-se como passos desnecessários para o processamento de peças e } \\
\text { produtos (Liker, 2005). }\end{array}$ \\
\hline $\begin{array}{l}\text { Desperdício de estoque } \\
\text { disponível (estoque) }\end{array}$ & $\begin{array}{l}\text { Ocorre quando há um excesso de matéria-prima, de estoque, de produtos em } \\
\text { processo ou estoque de produtos acabados (Liker, 2005). }\end{array}$ \\
\hline $\begin{array}{l}\text { Desperdício de movi- } \\
\text { mento }\end{array}$ & $\begin{array}{l}\text { Caracteriza-se pelos movimentos desnecessários realizados pelos trabalhadores } \\
\text { para a execução de uma operação, como: procurar, pegar ou empilhar peças ou } \\
\text { ferramentas (Ghinato, 1996; Liker, 2005). }\end{array}$ \\
\hline Desperdício por defeito & $\begin{array}{l}\text { Ocorre quando há a produção de produtos defeituosos ou fora da especificação } \\
\text { estabelecida pelo cliente (Ghinato, 1996). }\end{array}$ \\
\hline
\end{tabular}

Tabela 1. Tipos de desperdícios.

A busca pela eliminação de desperdícios e maximização dos resultados fez com que o lean migrasse da manufatura (ou chão de fábrica), em que foi concebido inicialmente, para outros ambientes. Desta forma sua nomenclatura foi acompanhando esses ambientes onde ele foi sendo utilizado, por exemplo: lean em serviços (lean services), lean em bancos (lean for banks), lean em startups e, mais recentemente, o uso dos princípios do lean em bibliotecas.

\section{Lean e as bibliotecas}

Partindo dos princípios do lean thinking, Nelson (2011) sugere adaptá-los ao contexto das bibliotecas a partir das seguintes perguntas: qual o valor da biblioteca para o usuário? Quais processos ou fluxos de trabalho na biblioteca fornecem esse valor? Como a biblioteca pode tornar as operações envolvidas com o fluxo de valor mais transparente e com menos desgaste? Onde estão os usuários da biblioteca que usam seus serviços? Como os desejos e as necessidades deles devem ser coletados? Como a biblioteca está respondendo a essas demandas em seus fluxos de trabalho? Quais são as métricas e os resultados que demonstram que a biblioteca está cumprindo ou excedendo as demandas dos usuários por recursos e serviços?

A resposta para essas perguntas leva a biblioteca a refletir sobre o seu desempenho na entrega de valor aos usuários. Nelson (2011) destaca que implementar todos os princípios do lean não é uma tarefa fácil e muitas vezes os resultados podem ser não tão óbvios assim. Implementá-lo requer o comprometimento da alta gestão da biblioteca e de um movimento para a mudança da cultura institucional (Huber, 2011; Nelson, 2011).

Bremner (2016) destaca que o respeito às pessoas é a chave do lean. Portanto, para que elas colaborem com as mudanças, é necessário envolvê-las, a fim de transformar a cultura resistente à mudança (Huber, 2011). Cervone (2015) afirma que os esforços para a consecução do lean devem ser sempre direcionados para a descoberta e resolução dos problemas que impedem que a organização atinja os seus objetivos. Huber (2011) complementa também que para isso é necessário que as pessoas entendam o propósito organizacional, a partir da definição da missão e visão da biblioteca e da definição do seu papel dentro desse propósito.

O esforço para a melhoria com a utilização do lean exige que a biblioteca seja vista como um sistema, por isso é necessário que os gestores que conduzem a mudança foquem em toda a cadeia de prestação de serviços, e não apenas em melhorias pontuais (Huber, 2011). Para isso, é preciso que os envolvidos no processo de mudança conheçam todo o fluxo de prestação do serviço, pois muitas vezes as pessoas se concentram apenas no desempenho das atividades do seu setor, perdendo a noção do todo, o que pode criar barreiras na comunicação e na relação entre setores (Huber, 2011).

Em termos práticos, iniciar o uso dos princípios do lean na biblioteca envolve criar uma equipe multifuncional (Huber, 2011; Locher, 2011). Ou seja, essa equipe deve ser formada por profissionais de diversas áreas da biblioteca, pois removem as paredes departamentais, desinibindo a comunicação (Huber, 2011). 
Posteriormente, é necessário o planejamento a partir de uma análise dos fluxos de valor desenvolvidos na biblioteca. Essa análise, ocorre a partir da elaboração do MFV cujo objetivo será para retratar o estado atual e o futuro. O MFV do estado atual representa a forma como o serviço é realizado. Ele reúne informações sobre o processo que desenvolve o serviço de forma visual (Keyte \& Locher, 2004). Já o mapa do estado futuro foca na direção de um fluxo de valor e seu desempenho pretendido, e o plano de ação descreve as melhorias necessárias e os prazos para atingi-las (Keyte \& Locher, 2004).

Ao longo do processo de construção do MFV e da implementação das melhorias, é necessário o desenvolvimento de métricas de desempenho, pois as mudanças ocorrem por algum motivo. As pessoas precisam entender por onde começarão e aonde querem chegar (Huber, 2011). As métricas, além de ajudar as pessoas a verem a necessidade da mudança, auxiliam na avaliação do seu o progresso, ajudam a identificar o custo, o serviço e a qualidade do fluxo de valor. Na Tabela 2 estão descritas algumas métricas definidas por Keyte e Locher (2004).

\begin{tabular}{|c|c|}
\hline Métrica & Significado \\
\hline Tempo de processo (P/T) & É o tempo real necessário para completar uma atividade. \\
\hline Tempo de execução (L/D) & $\begin{array}{l}\text { É o tempo decorrido associado à conclusão de uma atividade, incluindo as ativi- } \\
\text { dades que agregam ou não valor. }\end{array}$ \\
\hline Tempo de valor agregado & Refere-se ao tempo realmente gasto nas atividades que agregam valor. \\
\hline Tempo de mudança & É o tempo necessário para mudar de uma atividade para outra. \\
\hline Taxa de demanda & $\begin{array}{l}\text { Representa o volume de transações observadas em cada processo durante um } \\
\text { período especificado. }\end{array}$ \\
\hline Acurácia (C\&A) & $\begin{array}{l}\text { Descreve a frequência com que uma atividade recebe informações completas e } \\
\text { precisas. }\end{array}$ \\
\hline Número de pessoas & $\begin{array}{l}\text { Está relacionado com a quantidade e capacidade das pessoas responsáveis por } \\
\text { realizar a atividade ou o processo. }\end{array}$ \\
\hline Estoque & $\begin{array}{l}\text { Representa as filas de informações aguardando para serem processadas ou falta } \\
\text { de fluxo de informação. }\end{array}$ \\
\hline Tecnologias & Descreve as ferramentas de software e hardware usadas. \\
\hline Tempo disponível & $\begin{array}{l}\text { É a quantidade de tempo que uma empresa é capaz de executar um processo ou } \\
\text { processos específicos. }\end{array}$ \\
\hline
\end{tabular}

Tabela 2. Métricas para avaliar desempenho de fluxos administrativos.

Fonte: Adaptado de "The complete lean enterprise: value stream mapping for administrative and office processes", de Keyte e Locher (2004)

Em suma, as métricas de desempenho ajudam a entender a necessidade de mudança e avaliar o seu impacto (Huber, 2011).

\section{MÉTODO}

Para atender o objetivo proposto, foi realizado um grupo focal, no qual participaram dois bibliotecários, um assistente em administração e um estagiário, todos pertencentes ao quadro funcional da BC da UFSC. O que motivou a escolha do grupo focal foi que esta é uma técnica de coleta de dados que visa a participação de pessoas tendo em vista atingir um determinado objetivo, o que tem aderência direta ao lean, pois esse prevê que o envolvimento das pessoas impulsiona as mudanças na organização.

O critério utilizado para a seleção dos participantes foi o contato direto que possuíam com o serviço de empréstimo para os alunos da EaD. Os participantes foram convidados via e-mail institucional, no qual foi descrito o objetivo da pesquisa e um breve cronograma das discussões.

O local da pesquisa foi na BC, unidade vinculada aos Sistema de Bibliotecas da UFSC, responsável por executar o serviço analisado a partir das solicitações dos alunos da graduação vinculadas aos cursos da EaD da Universidade Aberta do Brasil.

Durante as três sessões do grupo focal, foi possível socializar os conhecimentos adquiridos pela pesquisadora sobre o lean, analisar o serviço de empréstimo EaD e elaborar os MFV na perspectiva atual e futura, a partir de Keyte e Locher (2004). As etapas são:

a) documentar a informação e a necessidade do cliente: consiste em verificar o que o cliente precisa, quanto e para quando ele precisa. Foram verificadas as necessidades dos usuários do serviço expressas pelo e-mail institucional do serviço de empréstimo EaD, por isso o foco foi buscar diminuir o tempo que o material demora para chegar ao usuário desde a sua solicitação;

b) identificar processos principais (em ordem): é importante que sejam identificados os caminhos que a informação percorre, o que muitas vezes envolve mais de uma pessoa ou setor. Os processos foram identificados a partir da observação das atividades que a(s) pessoa(s) o executavam para realizar o empréstimo, posteriormente o detalhamento dessas atividades ocorreu durante as discussões do grupo focal; 
c) selecionar métricas de processo: cujo objetivo é medir o desempenho do processo. No âmbito dessa pesquisa foram selecionadas as métricas: tempo de processo, tempo de execução, acurácia, número de pessoas, estoque, tecnologias e recursos utilizados. A aferição dos tempos foi realizada a partir da cronometragem das atividades durante sua execução. A cronometragem ocorreu três vezes, no mapa foi registrado o maior e o menor tempo de cada atividade.

d) desenhar os $M F V$ : consiste na efetivação do MFV. Durante as sessões do grupo focal, os MFV foram elaborados em cartolinas e com o uso de post its para a definição da sequência das atividades;

e) estabelecer como cada processo prioriza o trabalho: observar como a equipe prioriza as atividades, como ela organiza seu trabalho. A priorização foi discutida com os servidores que participaram do grupo focal;

f) calcular as métricas definidas: nesta etapa, é possível verificar o desempenho do serviço analisado. A partir da coleta dos tempos através da cronometragem, os tempos foram calculados e registrados nos mapas;

g) elaborar os planos de ação: a partir do diagnóstico subsidiado pelos mapas, foi possível identificar as oportunidades de melhoria, definir onde iriam começar as mudanças, os setores envolvidos e quais prazos a serem cumpridos.

Em síntese, o MFV prepara o ambiente para a transformação enxuta, identificando os desperdícios e as oportunidades de melhoria, estabelecendo um foco e uma direção para essa transformação (Keyte \& Locher, 2004).

\section{RESULTADOS}

A BC oferece um serviço de empréstimo, cujo objetivo é possibilitar que os alunos dos cursos a distância que moram longe dos campi da UFSC possam solicitar o empréstimo de materiais. O serviço funciona da seguinte maneira: o aluno solicita o material via e-mail e, após constatar sua disponibilidade nos acervos das bibliotecas do Sistema de Bibliotecas da UFSC, esse material é encaminhado via serviço de entrega de correspondências ao aluno solicitante. Devido a essa característica de encaminhar o material até o aluno, e não de o aluno vir até a biblioteca retirá-lo, como é realizado no empréstimo presencial, o serviço analisado tem algumas especificidades na sua cadeia de valor que geram uma maior burocracia.

Para elaborar o MFV atual, foi necessário ir ao gemba, ou seja, verificar como o serviço se desenvolve na prática para realizar a validação do mapa e a cronometragem dos tempos. Na Figura 1, está apresentado o resultado deste trabalho e, após, é realizada sua descrição.

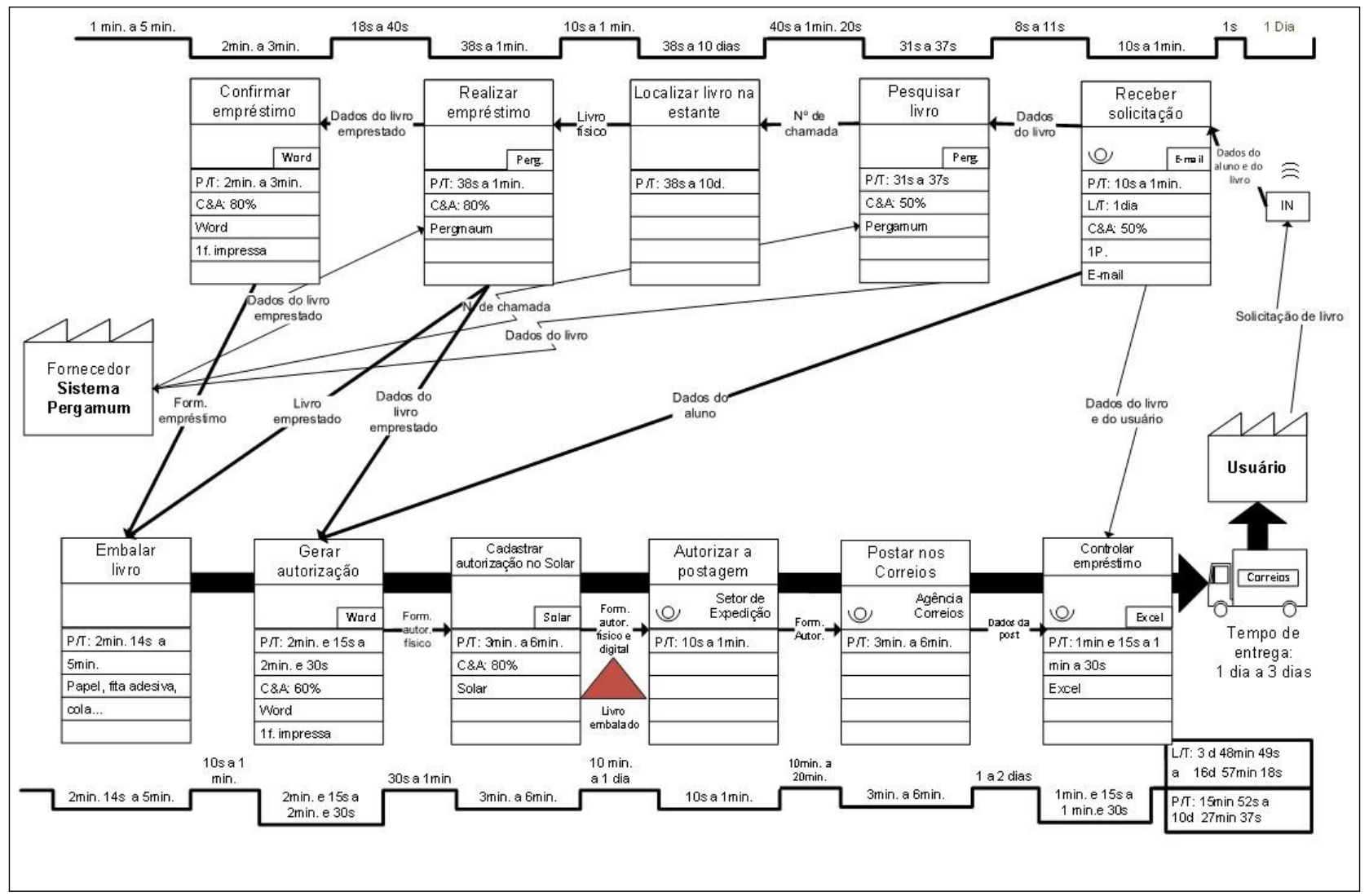

Figura 1. MFV atual do serviço de empréstimo EaD. 
O MFV é construído e lido da direita para a esquerda, na parte de cima e de baixo da figura estão descritos o intervalo de tempo em que cada atividade ocorre, abaixo de cada atividade estão descritas as métricas envolvidas, sendo que:

a) o fluxo inicia com o aluno encaminhando um e-mail, solicitando o empréstimo de determinado livro para o bibliotecário da BC responsável por esse serviço;

b) o e-mail fica aguardando receber algum encaminhamento, enquanto o bibliotecário verifica no sistema Pergamum se o aluno é vinculado a EaD;

c) após a verificação dos dados do aluno e de posse dos dados do livro, é necessário verificar no sistema Pergamum a disponibilidade do material. Caso ele esteja disponível, é anotado o número de chamada que permite a localização do livro na estante;

- para localizar o livro na estante, são necessários de 38 segundos a dez dias. Essa variação se deve a dois fatores: primeiro a dificuldade de localizar o livro dentro da biblioteca, caso ele não esteja guardado no local correto; segundo, o livro pode estar localizado nas bibliotecas setoriais, e como elas não estão aptas a realizarem esse serviço, é necessário que o bibliotecário se desloque até a setorial para localizar o livro ou, caso seja uma setorial fora de Florianópolis, é necessário solicitar esse material via malote;

d) de posse do livro é necessário efetivar o empréstimo ao aluno solicitante no sistema Pergamum. Esse processo tem duas saídas: a primeira é o livro emprestado que será encaminhado para o processo de embalagem; e a segunda são os dados do livro emprestado, que irá compor o processo de confirmação de empréstimo, cujo objetivo é informar ao aluno quais os títulos e os exemplares foram emprestados a ele;

e) para embalar o material, é necessário, ainda se deslocar para encontrar os materiais que serão utilizados (tesoura, papel pardo, cola, fita adesiva etc.);

f) reunidos os materiais, procede-se o processo de empacotamento do material;

g) com o material já embalado, é preciso preencher o formulário de solicitação de emissão de Sedex no serviço de entrega de correspondências;

h) paralelo ao preenchimento desse formulário, é necessário cadastrá-lo no sistema administrativo Solar (também conhecido como SPA) e gerá-lo na versão digital;

i) o livro empacotado e o formulário para solicitação de emissão de Sedex são encaminhados para a Secretaria da Direção, onde ficam aguardando a disponibilidade de outro servidor para encaminhá-lo ao Serviço de Comunicação e Expedição da UFSC;

j) o servidor leva o material e o formulário até o Serviço de Comunicação e Expedição, onde o preenchimento do formulário é conferido e autorizado para ser postado na Agência do serviço de entrega de correspondências;

k) após a conferência, o servidor da biblioteca encaminha-se até a Agência do serviço de entrega de correspondências para realizar a postagem e o despacho do material para o endereço solicitado pelo aluno;

l) após o despacho do material, é gerado o comprovante de postagem, e nesse comprovante é descrito o código de rastreamento do material. O tempo necessário para entrega serviço de entrega de correspondências ao aluno solicitante gira em torno de um a três dias;

m) por fim, com o comprovante da postagem, é realizado o controle do empréstimo a partir do preenchimento da planilha de Estatística do Serviço que é utilizada para controlar o envio dos materiais solicitados e para embasar o Relatório gerencial.

Analisando o MFV atual, é possível identificar as atividades que agregam ou não valor para o serviço, conforme Tabela 3. Cabe ressaltar que as atividades que Agregam Valor (AV), são aquelas que contribuem para a efetivação do serviço, as atividades que Não Agregam Valor (NAV) são aquelas que não contribuem, apesar disso, elas podem ser divididas em atividades que NAV, mas são necessárias (N) e aquelas que NAV, e são desnecessárias (D), os desperdícios.

Ao analisar a Tabela 3, verifica-se que o $\mathrm{P} / \mathrm{T}$ do empréstimo EaD, ou seja, o tempo que as atividades levam para ser concluídas a partir do recebimento da solicitação do aluno, pode variar de 15 minutos e 52 segundos a dez dias 57 minutos e 37 segundos. Essa variação está relacionada àqueles casos em que o livro pertence ao acervo de alguma biblioteca setorial fora de Florianópolis, mas como esse serviço é oferecido apenas pela BC, então é necessário aguardar o deslocamento do livro da setorial até Florianópolis.

Já o tempo que o usuário leva para receber o material a partir da sua solicitação pode variar de três dias 48 minutos e 49 segundos a 16 dias 57 minutos e 18 segundos, incluindo nesse tempo o transporte do material até o usuário. Esse tempo que o usuário leva para receber o material é chamado de tempo de execução (ou lead time).

Nesse tempo estão incluídos o tempo de mudança entre os processos, que pode variar de 1 minuto e 6 segundos a 2 minutos e 51 segundos. O tempo de estoque, está relacionado ao tempo que a solicitação do aluno ficou 


\begin{tabular}{|c|c|c|c|c|c|}
\hline \multirow{2}{*}{ Atividades } & \multicolumn{3}{|c|}{ Tipo de atividade } & \multicolumn{2}{|l|}{ Métricas } \\
\hline & AV & NAV & N/D & $\begin{array}{l}\text { Tempo de processamento } \\
\text { (T/P) }\end{array}$ & Tempo de execução \\
\hline Receber solicitação & AV & & $\mathrm{N}$ & 10s a $1 \mathrm{~min}$. & \\
\hline Pesquisar livro & & NAV & $\mathrm{D}$ & 31s a 37s & \\
\hline Localizar livro na estante & AV & & $\mathrm{N}$ & 38s a $10 \mathrm{~d}$. & \\
\hline Realizar empréstimo & AV & & $\mathrm{N}$ & $38 \mathrm{~s}$ a $1 \mathrm{~min}$. & \\
\hline Confirmar empréstimo & & NAV & $\mathrm{D}$ & $2 \min$. a $3 \min$. & \\
\hline Embalar material & AV & & $\mathrm{N}$ & 2 min. 14s a 5 min. & \\
\hline Gerar autorização & & NAV & $\mathrm{N}$ & $2 \min .15 \mathrm{~s}$ a $2 \mathrm{~min} .30 \mathrm{~s}$ & \\
\hline $\begin{array}{l}\text { Cadastrar autorização no } \\
\text { Solar }\end{array}$ & & NAV & $\mathrm{N}$ & 3min. a 6min. & \\
\hline Autorizar a postagem & & NAV & $\mathrm{D}$ & 10s a $1 \mathrm{~min}$. & \\
\hline $\begin{array}{l}\text { Postar no serviço de en- } \\
\text { trega de correspondências }\end{array}$ & AV & & $\mathrm{N}$ & 3min. a 6min. & \\
\hline Controlar empréstimo & & NAV & D & $1 \mathrm{~min}$ e $15 \mathrm{~s}$ a $1 \mathrm{~min}$ a $30 \mathrm{~s}$ & \\
\hline \multicolumn{4}{|l|}{ TOTAIS } & $\begin{array}{l}\text { 15min. 52s a } \\
10 \mathrm{~d} 57 \mathrm{~min} .37 \mathrm{~s}\end{array}$ & $\begin{array}{l}\text { 3d 48min 49s a } \\
16 d 57 \min 18 s\end{array}$ \\
\hline
\end{tabular}

Tabela 3. Análise do MFV atual.

Nota: Nota. Legenda: AV - Agrega Valor; NAV - Não agrega valor; N - Necessária; D - Desnecessária.

aguardando ser atendida, o que pode levar em torno de um dia, e o tempo que o livro embalado ficou parado esperando ser encaminhado para a postagem no serviço de entrega de correspondências, variou de 10 minutos a dois dias.

Ainda no tempo de execução está incluído o tempo de deslocamento dos servidores com os materiais, que pode variar de 1 minuto e 50 segundos a 7 minutos e 20 segundos, e o tempo de espera, que nesse caso representa a espera em filas aguardando atendimento e espera para receber o material encaminhado pelas bibliotecas setoriais, pode variar de um 1 e 10 minutos a 10 dias e 20 minutos.

Quanto aos recursos empregados para a efetivação do empréstimo EaD, estão envolvidas quatro pessoas, é necessária a impressão de duas folhas e materiais como papel pardo, fita adesiva, cola etc. para embalar os livros. Quanto às tecnologias envolvidas, nesse caso, é necessário manusear simultaneamente o e-mail, o sistema Pergamum, o Word, o Excel e o sistema Solar. Ressalta-se também que tanto o e-mail quantos os sistemas Pergamum e Solar exigem que o bibliotecário use contas e senhas diferentes.

No entanto, se analisarmos apenas aquelas atividades que agregam valor, seriam necessários apenas seis minutos e 41 segundos a 10 dias e 13 minutos para processar a solicitação do aluno.

Ao analisar todas as atividades na perspectiva dos desperdícios de Ohno (1997), verifica-se que o desperdício de espera é que mais causa ônus para o serviço e para o aluno, seu tempo total varia de 13 dias e 29 minutos e 40 segundos a 16 dias e 39 minutos, conforme Tabela 4 .

\begin{tabular}{|l|l|l|}
\hline Tipo de desperdício & Processo & Tempo \\
\hline Superprodução & Confirmar empréstimo & 2min. a 3 min. \\
\hline \multirow{3}{*}{ Tempo disponível (espera) } & Aguardar a chegada do livro da setorial & 10dias \\
\cline { 2 - 3 } & $\begin{array}{l}\text { Aguardar na fila para ser atendido na Agên- } \\
\text { cia do serviço de entrega de correspondên- } \\
\text { cias }\end{array}$ & 10min. a 20 min. \\
\cline { 2 - 3 } & $\begin{array}{l}\text { Aguardar comprovante da postagem para } \\
\text { realizar o controle de empréstimo }\end{array}$ & 1dia a 2 dias \\
\hline Transporte & $\begin{array}{l}\text { Transporte do material até o usuário que } \\
\text { solicitou }\end{array}$ & 1dia a 3 dias \\
\hline \multirow{5}{*}{ Processamento } & Gerar autorização & 2min. e 15s a 2min. e 30s \\
\cline { 2 - 3 } & Cadastrar autorização no Solar & 3min. a 6 min \\
\cline { 2 - 3 } & Autorizar a postagem & $10 \mathrm{~s} \mathrm{a} \mathrm{1min.}$ \\
\cline { 2 - 3 } & Controlar empréstimo & 1min. e 15s a 1 min. e 30s \\
\hline \multirow{2}{*}{ Estoque } & $\begin{array}{l}\text { Tempo que a solicitação do aluno fica aguar- } \\
\text { dando ser atendida }\end{array}$ & 1 dia \\
\cline { 2 - 3 } & Livro embalado aguardando transporte & 10min. a 1 dia \\
\hline Movimento & Procurar materiais para embalar o livro & 1min. a 5 min. \\
\hline Tempo perdido com os desperdícios & 13d 29min 40s a 16d 39min \\
\hline
\end{tabular}

Tabela 4. Desperdícios no serviço de empréstimo EaD. 
Após analisar o MFV atual, com os participantes do grupo focal, foi possível identificar os desperdícios e as melhorias que podem tornar o fluxo das atividades envolvidas mais ágeis para os usuários e com menos ônus para a BC. São elas:

a) oferecer materiais online para os alunos, caso estes estejam disponíveis legalmente;

b) controlar o fluxo a partir da definição de prioridades;

c) automatizar alguns processos;

d) delegar às bibliotecas setoriais a execução do serviço;

e) fundir algumas etapas;

f) excluir etapas;

g) formalizar o serviço, através de portaria;

h) criar manuais de procedimentos.

Por fim, com base na identificação dessas oportunidades de melhoria, foi elaborado o MFV na perspectiva futura, conforme Figura 2, onde fica definido o modelo ideal de serviço.

O MFV do futuro possibilita que gestores tenham uma visão "ideal" do serviço, partindo para o desenvolvimento das melhorias a serem executadas, a partir da definição do plano de ação com a descrição dos responsáveis por executá-las e os prazos para concretizá-las.

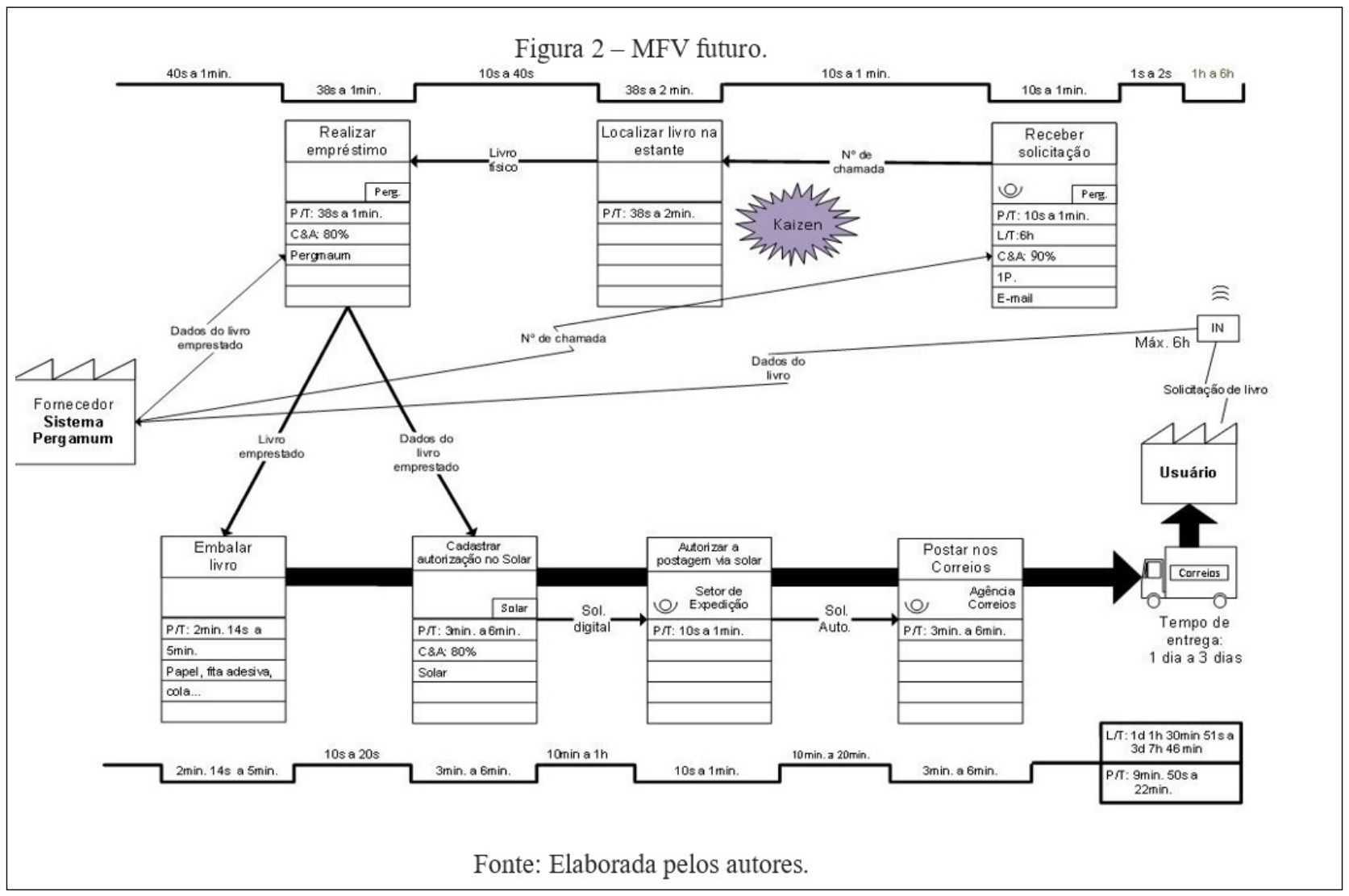

Figura 2. MFV futuro.

Ainda a partir da análise da Figura 2, é possível verificar que aquelas atividades que agregam valor ao processo de execução do serviço de empréstimo EaD foram mantidas e muitas foram otimizadas tendo seu tempo de execução reduzido. Comparando o fluxo atual do serviço com o fluxo futuro, percebe-se que houve uma economia significativa de tempo. Na Tabela 5, está descrita essa comparação.

A construção dos MFV e a identificação das melhorias somente foi possível devido ao envolvimento dos servidores que participaram no grupo focal. Portanto, o envolvimento das pessoas é muito importante, pois elas são a peça-chave no lean e são elas que trabalham diretamente nos processos (Bremner, 2016; Huber, 2011; Kress, 2008). 


\begin{tabular}{|l|l|l|}
\hline & MFV atual & MFV futuro \\
\hline L/T & 3d 48min 49s a & 1d 1h 30min e 51s a \\
& 16d 57min 18s & 3d 7h 56 min \\
\hline P/T & 15min 52s a & 9 mine 50 s a \\
& 10d 57min 37s & 22 min. \\
\hline
\end{tabular}

Tabela 5. Comparação de tempo entre o MFV atual e futuro.

\section{CONSIDERAÇÕES FINAIS}

Diante dos dados apresentados pode-se afirmar que o MFV pode contribuir para a identificação das oportunidades de melhorias do serviço de empréstimo EaD na UFSC. No entanto, isso somente é possível com o envolvimento das pessoas que executam os processos e atividades e apoio da gestão. A elaboração do MFV, a ida ao gemba e a discussão com os servidores envolvidos na pesquisa possibilitou verificar que esse serviço possui muitos desperdícios, sendo o principal deles o desperdício por espera.

No entanto, cabe ressaltar que a filosofia lean não é uma receita pronta em que os modos de aplicação utilizados numa instituição podem ser generalizados para outras. Isso leva-nos a ressaltar que esta pesquisa foi aplicada no contexto da BC da UFSC, com suas peculiaridades e num determinado período de tempo. Por isso, os resultados desta pesquisa não são generalizáveis.

A identificação de desperdícios é uma premissa que precisa ser assumida pelas bibliotecas para que dessa forma possam usar seus recursos de maneira mais racional. Portanto, o MFV é uma importante ferramenta que junto com suas métricas auxilia que os bibliotecários gestores de bibliotecas possam realizar um diagnóstico da eficiência dos serviços, tornando explícitos os desperdícios envolvidos. Cabe salientar que após os desperdícios serem identificados é preciso o comprometimento de todos para que o movimento da melhoria contínua traga resultados e leve a biblioteca rumo à melhoria contínua de sua atuação nas necessidades dos usuários.

Espera-se que os bibliotecários se apropriem dessas ferramentas para identificar desperdícios e possibilitar a revisão de suas práticas laborais. 


\section{REFERÊNCIAS}

Barbosa, M. P. (2014). Abordagem lean ao processo de aquisição de monografias do ISCTE-IUL [Dissertação de Mestrado]. Instituto Universitário de Lisboa. Recuperado de https://repositorio.iscte-iul.pt/handle/10071/10168

Bremner, J. (2016). Lean in the library: building capacity by realigning staff and resources. In A. Mackenzie \& L. Martin (Eds.), Developing Digital Scholarship: emerging practices in academic libraries. London: Facet Publishing.

Cabete, M. S., Cabete, N. P. F., \& Melo, D. R. A. (2016a). Acervo enxuto para biblioteca escolar. Biblionline, 12(2), 3626. Recuperado de https://periodicos.ufpb.br/ojs2/index .php/biblio/article/view/27702

Cabete, M. S., Cabete, N. P. F., \& Melo, D. R. A. (2016b). Lean office e as cinco leis da biblioteconomia: possibilidades para gestão de bibliotecas. Revista FOCO, 9 (1), 215-232. Recuperado de https://core.ac.uk/download/pdf/204828399 .$p d f$

Cavaglieri, M., \& Juliani, J. P. (2016). Implantação do sistema kanban como instrumento de controle dos documentos. Ágora, 25(52), 119-142. Recuperado de https:// agora.emnuvens.com.br/ra/article/view/595

Cavaglieri, M., \& Juliani, J. P. (2017a). Implantação do sistema $5 \mathrm{~s}$ na gestão de arquivos. Informação em Pauta, 2(1), 73-95. Recuperado de http://periodicos.ufc.br/ informacaoempauta/article/view/6663

Cavaglieri, M., \& Juliani, J. P. (2017b). Lean archives: O emprego do lean office na gestão de arquivos. Perspectivas em Ciência da Informação, 21, 180-201. Recuperado de http://portaldeperiodicos.eci.ufmg.br/index.php/ pci/article/view/2726

Cervone, H. F. (2015). Information organizations and the lean approach to service delivery. OCLC Systems 8 Services: International digital library perspectives, 31(4), 158-162. Recuperado de http://dx.doi.org/10.1108/OCLC $-07-2015-0007$

Durán, M. G. G. (2014). Aplicación de la metodología lean en bibliotecas y centros de documentación [Dissertação de Mestrado]. Universid de Alcalá.. Recuperado de http:// hdl.handle.net/10017/23037

Ferreira, A. A. J., \& Mota, A. P. C. (2019). Modelagem de processos em bibliotecas universitárias: aplicações em serviços de atendimento. Biblos, 33(1), 67-93. Recuperado de https://doi.org/10.14295/biblos.v32i2.7957

Freitas, R. D. C., Silva, H. N., Odorczyk, R. S., \& Freitas, M. D. C. D. (2018, jun). Práticas do pensamento enxuto para a gestão estratégica da informação e do conhecimento. Encontros Bibli: revista eletrônica de biblioteconomia e ciência da informação, 76-89. Recuperado de https://doi.org/10.5007/1518-2924.2018v23nespp76 doi: 10.5007/1518-2924.2018v23nespp76

Ghinato, P. (1996). Sistema toyota de produção: mais do que simplesmente just-in-time. Caxias do Sul: Educs.

Greef, A. C., \& Freitas, M. d. C. D. (2012). Fluxo enxuto de informação: um novo conceito. Perspectivas em Ciência da Informação, 17(1), 37-55. Recuperado de http://portaldeperiodicos.eci.ufmg.br/index.php/ $\mathrm{pci} /$ article/view/1246

Huber, J. J. (2011). Lean Library Management: eleven strategies for reducing and improving customer services. Nova York: Neal-Schuman Publishers.
Keyte, B., \& Locher, D. (2004). The complete lean enterprise: value stream mapping for administrative and office processes. New York: Productivity Press.

Kress, N. J. (2008). Lean thinking in libraries: a case study on improving shelving turnaround. Journal of Access Services, 5(1), 159-172. Recuperado de https://www .tandfonline.com/doi/abs/10.1080/15367960802198606 doi: $10.1080 / 15367960802198606$

Liker, J. K. (2005). O modelo Toyota: 14 princípios de gestão do maior fabricante do mundo. Porto Alegre: Bookman.

Locher, D. (2011). Lean office and service simplified: the definitive how-to guide. Boca Raton, FL: CRC Press.

Marques, M. B. (2016). A determinação do valor das bibliotecas universitárias na Sociedade da Informação e do Conhecimento. In J. A. C. Bernardes, A. M. E. Miguéis, \& C. A. S. Ferreira (Eds.), A biblioteca da Universidade: permanência e metamorfoses. Coimbra: Ed. Imprensa da Universidade de Coimbra. Recuperado de https://digitalis -dsp.uc.pt/jspui/handle/10316.2/36981

Martignago, D., \& Juliani, J. P. (2019). Reduzindo o tempo de publicação de um manuscrito em um periódico de acesso aberto: um estudo baseado na filosofia lean. RDBCI: Revista Digital de Biblioteconomia e Ciência da Informação, 17(1), 1-23. Recuperado de https://doi.org/10.20396/rdbci.v17i0 .8655304

Martignago, D., \& Juliani, J. P. (2020). A especificação de valor como princípio para tornar o processo editorial de periódicos científicos enxuto na perspectiva dos autores. Revista Brasileira de Biblioteconomia e Documentação, 16 1-23. Recuperado de http://hdl.handle.net/20.500.11959/ brapci/ 145573

Nelson, J. (2011). Becoming a lean library: lessons from the world of technology start-ups. Waltham, MA: Chandos Publishing.

Nilofar, S. (2017). Leveraging the principles of lean six sigma in creating value for the user community. In Proceedings of the 38th iatul conferences (v. 28, p. 1-14). Italy. Recuperado de https://docs.lib.purdue.edu/iatul/2017/spaces/5

Ohno, T. (1997). O Sistema Toyota de Produção: além da produção em larga escala. Porto Alegre: Bookman.

Regan, C.-A., Goldsworthy, S., \& Pawley, J. (2020). Optimising real time clinical librarian support to enhance the evidence base in radiotherapy clinical protocols. Library and Information Research, 43(127), 1-14. Recuperado de https://doi.org/10.29173/lirg809

Valentim, M. L. P. (2017). O perfil das bibliotecas contemporâneas. In A. C. M. Ribeiro \& P. C. G. Ferreira (Eds.), Biblioteca do século XXI: desafios e perspectivas. Brasília: Ipea.

Womack, J. P., \& Jones, D. T. (1998). A mentalidade enxuta nas empresas: elimine o desperdício e crie riqueza. Rio de Janeiro: Campus.

Yeh, S., Arthaud-Day, M., \& Turvey-Welch, M. (2021). Propagation of lean thinking in academic libraries. The Journal of Academic Librarianship, 47(1), 1-6. Recuperado de https://doi.org/10.1016/j.acalib.2021.102357

Como citar este artigo (APA):

Silveira, C. Z. \& Juliani, J. P. (2022). Eliminando desperdícios na biblioteca: o uso do Mapa do Fluxo de Valor (MFV) no serviço de empréstimo para educação a 
distância (EaD). AtoZ: novas práticas em informação e conhecimento, 11, 1 - 12. Recuperado de: http:// dx.doi.org/10.5380/atoz.v11.79536 


\section{FORMULÁRIO DE NOTAS DA OBRA E CONFORMIDADE COM A CIÊNCIA ABERTA}

\section{CONTRIBUIÇÃO DE AUTORIA}

\begin{tabular}{|l|c|c|}
\hline $\begin{array}{l}\text { Papéis } \\
\text { e contribuições }\end{array}$ & $\begin{array}{c}\text { Crislaine Zurilda } \\
\text { Silveira }\end{array}$ & $\begin{array}{c}\text { Jordan Paulesky } \\
\text { Juliani }\end{array}$ \\
\hline Concepção do manuscrito & $\mathrm{X}$ & $\mathrm{X}$ \\
\hline Escrita do manuscrito & $\mathrm{X}$ & $\mathrm{X}$ \\
\hline Metodologia & $\mathrm{X}$ & \\
\hline Curadoria dos dados & $\mathrm{X}$ & $\mathrm{X}$ \\
\hline Discussão dos resultados & $\mathrm{X}$ & $\mathrm{X}$ \\
\hline Análise dos dados & $\mathrm{X}$ & \\
\hline
\end{tabular}

\section{CONFORMIDADE COM A CIÊNCIA ABERTA}

\section{Disponibilidade de Dados Científicos da Pesquisa}

Os conteúdos subjacentes ao texto da pesquisa não podem ser disponibilizados publicamente.

Justificativa de não disponibilidade: Os dados brutos envolvem informações sobre a instituição e os participantes no momento da pesquisa não autorizaram a publicação das gravações.

\section{EQUIPE EDITORIAL}

\section{Editora/Editor Chefe}

Maria do Carmo Duarte Freitas (https://orcid.org/0000-0002-7046-6020)

\section{Editora/Editor Adjunta/Adjunto}

Paula Carina de Araújo (https://orcid.org/0000-0003-4608-752X)

\section{Editora/Editor de Texto Responsável}

Cristiane Sinimbu Sanchez (https://orcid.org/0000-0002-0247-3579)

Nicholle Ferreira Murmel Liali (https://orcid.org/0000-0002-1086-908X)

\section{Editora/Editor de Layout}

André José Ribeiro Guimarães (https://orcid.org/0000-0003-0874-7400) 